\title{
ANTIFUNGAL EFFECTS OF ALOE VERA IRRIGANT ON CANDIDA ALBICANS BIOFILM
}

\author{
ASTINAH, KAMIZAR NAZAR*, RATNA MEIDYAWATI
}

Department of Conservative Dentistry Faculty of Dentistry, Universitas Indonesia, Jakarta, Indonesia. E-mail: kamizar_kz@yahoo.com

\author{
Received: 27 August 2018, Revised and Accepted: 07 February 2019
}

\section{ABSTRACT}

Objective: Candida albicans tolerates unfavorable environmental conditions by forming biofilms, which can cause problems following endodontic treatments. $C$. albicans is the most common fungus found in failed root canals. Using natural irrigants with good antifungal properties for use as synthetic irrigant alternatives during root canal cleaning and shaping is very important. This study aimed to analyze the effects of Aloe vera on C. albicans biofilm.

Methods: C. albicans biofilm was divided into the following five groups: Group I, no treatment (control group); Groups II, III, and IV, A. vera with a concentration of 100\%, 75\%, and 50\%, respectively; and Group V, Ethylenediaminetetraacetic acid (EDTA) 17\%.

Results: The average biofilm colony count for C. albicans for the A. vera $100 \%, 75 \%$, and 50\% groups was higher than that for the EDTA $17 \%$ group but lower than that for the control group.

Conclusion: A. vera has antifungal effects on C. albicans biofilm, with the greatest effect occurring at $75 \%$ concentration.

Keywords: Candida albicans, Biofilm, Aloe vera.

(C) 2019 The Authors. Published by Innovare Academic Sciences Pvt Ltd. This is an open access article under the CC BY license (http://creativecommons. org/licenses/by/4. 0/) DOI: http://dx.doi.org/10.22159/ijap.2019.v11s1.AR151

\section{INTRODUCTION}

Candida albicans is a common fungus that is present in $3-18 \%$ of failed root canal cases [1,2]. Waltimo et al. noted that microorganisms such as fungi that are resistant to endodontic treatment can cause secondary infections [3]. Of 692 cases of the failed root canal, 47 (7\%) were fungi-related and 48 species of the fungus were identified. Of these, C. albicans was the most common fungus found. Sureshchandra and Arun have revealed that $C$. albicans is a resistant microorganism, has dentinophilic properties, and shows affinity on the smear layer [4]. In addition, Sureshchandra and Arun. have revealed that $C$. albicans can survive in the root canal even after root canal cleaning and shaping [4].

C. albicans has several strategies for tolerating unfavorable environmental conditions, such as by altering its morphology from yeast to hyphae, immunomodulating the host defense system, and adapting to any $\mathrm{pH}$ environment. In addition, $C$. albicans can form biofilms, perform thigmotropism (contact sensing) to penetrate dentine tubules, switch phenotypes, and produce proteolytic enzymes [1,3,5].

The success of endodontic treatment depends on the elimination of microorganisms such as C. albicans from the rootcanal system. Grossman has highlighted the need to eliminate such organisms to maintain the periapical tissue normal or restore periapical tissue to a healthy stage after root canal $[1,4,5]$. Thus, the use of an irrigant with good antifungal properties is very important during root canal cleaning and shaping. A study by Ghogre has shown that ethylenediaminetetraacetic acid (EDTA) $17 \%$ has better antifungal properties than $\mathrm{NaOCl} 5 \%$ and Savrolin (1.5\% CHX and 15\% Cetrimide). The antifungal potential of EDTA $17 \%$ is due to its ability to dissolve the calcium ions involved in the morphogenesis and pathogenesis of $C$. albicans. The expression of hyphal wall protein 1 (HWP1), a $C$. albicans gene associated with the formation of biofilm, was successfully reduced by EDTA $[1,5,6]$.

The use of natural, rather than synthetic, ingredients to kill fungi is of interest because natural ingredients are more acceptable, their raw materials are easier to obtain, they have fewer side effects, and their costs are lower $[7,8]$. Agarry et al. have reported that $A$. vera, both in gel and leaf forms, inhibits the growth of $C$. albicans. This finding is supported by a study by Fitriani showing that $A$. vera $25 \%$ is adequate for inhibiting the growth of $C$. albicans planktonic type bacteria and that $A$. vera extract $75 \%$ is adequate for eliminating $C$. albicans $[3-5,9-11]$. However, comparative studies of EDTA $17 \%$ and A. vera as irrigants have not been conducted. Thus, this study aimed to produce an effective irrigant against the most commonly found fungus $C$. albicans in failed root canal treatment.

\section{METHODS}

This study was conducted at the Oral Biology Laboratory, Oral Biology Department, Faculty of Dentistry, Universitas Indonesia. The effectiveness of irrigants on $C$. albicans biofilms was assessed by calculating the colony-forming units (CFUs). C. albicans used in this study was a pure strain of American Type Culture Collection $10231^{\mathrm{TM}}$. The use of seed stock minimizes the subculture method and has good protective and storage protocols for maintaining the safety and effectiveness of the culture [12]. C. albicans ATCC 10231 is a purified C. albicans laboratory subculture that can grow as a biofilm and has been widely used as a representative strain in clinical and laboratory studies [10,13,14].

C. albicans ATCC 10231 was swabbed on Sabouraud Dextrose Agar (SDA) media until blended and then incubated for $24 \mathrm{~h}$ at $37^{\circ} \mathrm{C}$. After culture, C. albicans was obtained using needles up to one full loop, inserted into a tube containing $10 \mathrm{ml}$ of Sabouraud Dextrose broth solution, and incubated for $24 \mathrm{~h}$ at $37^{\circ} \mathrm{C}$. To produce biofilm, $10 \mu \mathrm{l}$ of $C$. albicans was prepared by adding $10 \mu \mathrm{l}$ of Sabouraud Dextrose broth and then incubating at $37^{\circ} \mathrm{C}$ for $24 \mathrm{~h}$. To obtain $100 \%$ A vera solution, $5 \mathrm{~g}$ of dried $A$. vera extract was placed in a $50-\mathrm{ml}$ flask with $50-\mathrm{ml}$ aquadest. To obtain $75 \%$ A vera solution, $7.5 \mathrm{ml}$ of $100 \%$ A vera solution was pipetted into a $10-\mathrm{ml}$ flask with 10 -ml aquadest. To obtain $50 \%$ A. vera solution, $5 \mathrm{ml}$ of $100 \%$ A. vera solution was pipetted into a 10 -ml flask with 10 -ml aquadest.

C. albicans biofilm was obtained using a micropipette until it ran out in each well. Subsequently, $200 \mu \mathrm{l}$ of the test material was applied to each 
well, except in the control, and allowed to sit for 1 min. Next, $100 \mu \mathrm{l}$ of phosphate buffer saline (PBS) was applied to each well. As much as, $10 \mu \mathrm{l}$ was transferred to a microtube and $990 \mu \mathrm{l}$ of PBS was added to obtain $10^{-2}$ dilutions. Of the $10^{-2}$ dilutions, $10 \mu \mathrm{l}$ was taken and mixed with $990 \mu \mathrm{l}$ of PBS to obtain $10^{-4}$ dilutions. Of the $10^{-4}$ dilutions, $10 \mu \mathrm{l}$ was taken and mixed with $990 \mu \mathrm{l}$ of PBS to obtain $10^{-6}$ dilutions. The $10^{-4}$ and $10^{-6}$ dilutions were then swabbed in each SDA medium coded according to the well design and incubated for $24 \mathrm{~h}$ at $37^{\circ} \mathrm{C}$.

Statistical analysis was conducted using SPSS 20.0 software. Shapiro-Wilk test demonstrated that data were normal, and one-way analysis of variance was used to assess differences among the groups. Tamhane's test was used for post hoc comparisons when data were not normally distributed. The level of statistical significance was set at $\mathrm{p}<0.05$.

\section{RESULTS}

Table 1 shows that the mean C. albicans biofilms colony count was the lowest for EDTA $17 \%$ (160.67 CFU/mL) and the highest for the untreated group (1852.67 CFU/mL). The mean values of the C. albicans biofilm colony count were lower for A. vera $100 \%, 75 \%$, and $50 \%$ groups than for the untreated group.

A. vera $75 \%$ showed a mean colony count of $863 \pm \pm 176.510$ (mean \pm SD), which was the lowest among $A$. vera $100 \%, 75 \%$, and $50 \%$, whereas A. vera $50 \%$ showed a lower mean colony count than $A$. vera $100 \%$. This indicates that $A$. vera $75 \%$ ( $863 \mathrm{CFU} / \mathrm{mL}$ ) had the best effects of all the concentrations tested.

In Table 2, A. vera $75 \%(\mathrm{p}=0.015)$, EDTA $17 \%$ without treatment $(\mathrm{p}=0.000)$, A. vera $100 \%$, EDTA $17 \%(\mathrm{p}=0.004)$, A. vera $50 \%$, and EDTA $17 \%$ groups showed a significant change. These findings suggest an antifungal effect of $A$. vera $75 \%$ and EDTA $17 \%$ and a better antifungal effect of EDTA $17 \%$ than A. vera $100 \%$ and $50 \%$.

\section{DISCUSSION}

This experimental study was aimed at observing the antifungal properties of A. vera as a new irrigant with antifungal potential against C. albicans biofilm.

Here, an antifungal efficacy test was conducted on C. albicans biofilm because biofilms are often found in teeth with persistent root canal infection, which is indicated for root canal treatment. According to Waltomi et al., C. albicans in root canal cases is present in the biofilm form; therefore, the evaluation of the effect of antifungal irrigant on C. albicans biofilm can better describe the conditions in root canals than described by bacterial culture studies of the planktonic form [3]. Fungi in biofilm form are more protected, particularly if there are smear layers, and can be more difficult to eliminate than planktonic fungi $[15,16]$. The differences in resistance to antifungal agents are much greater in species that are present in mature biofilms than similar species growing in the planktonic form. This is due to the virulence of C. albicans. Further, the hyphae were only found in C. albicans biofilm. In this study, biofilm was formed in a 96-well plate to allow its growth on standardized surfaces and incubated for $24 \mathrm{~h}$ because it has been estimated that $C$. albicans biofilms are formed within $24 \mathrm{~h}$, thus providing a more accurate assessment of the effectiveness of antifungal agents [17]. It was important to standardize the age of biofilms when comparing the effectiveness of antifungal agents [15].

A. vera has the ability to inhibit the growth of $C$. albicans, as supported by Sujatha et al. [16]. Components such as aloin, acemannan, and other ingredients found in A. vera play an important role as antifungals and immunomodulators that synergistically work, providing a promising outcome for the development of $A$. vera as an alternative irrigant in endodontic treatment. The selection of $100 \%, 75 \%$, and $50 \%$ concentrations of $A$. vera was based on previous studies that examined the effectiveness of $A$. vera on planktonic $C$. albicans.

Our results revealed that $A$. vera $75 \%$ has better antifungal properties than $A$. vera $100 \%$ and $50 \%$. This may be because $98-99 \%$ of the content of A. vera is water and the water content is still high at $100 \%$; thus, the mechanism of action of acemannan and aloin may not be optimally working. This finding contradicts with a previous study which found that a higher concentration of $A$. vera exhibits antifungal properties. This may be due to differences in the solution used to make A. vera extract. The previous study used ethanol, whereas aquadest was used in this study, which was also used by Fitriani $[6,11]$. Our findings are consistent with those previous studies which demonstrated the effectiveness of $A$. vera against $C$. albicans $[6,16]$.

Finally, both EDTA $17 \%$ and A. vera $75 \%$ showed statistically insignificant results; therefore, it was concluded that EDTA 17\% and A. vera $75 \%$ had the same antifungal potencies. EDTA $17 \%$ has an antifungal effect through its interaction in the cell walls of $C$. albicans that inhibits the growth and affects the nutritional condition of C. albicans. In addition, it can decrease the expression of the HWP gene and hyphae marker genes, which play an important roles in the formation of biofilm. Sen et al. have shown that EDTA $17 \%$ has a better antifungal potency as an irrigant against $C$. albicans than CHX, MTAD, and sodium hypochlorite $2.52 \%[2,9,14]$.

\section{CONCLUSION}

A. vera showed an antifungal effect on $C$. albicans biofilm. Further, A. vera $75 \%$ had a better antifungal effect than $A$. vera $100 \%$ and $50 \%$.

Table 1: Mean C. albicans biofilm colony count (in $\mathrm{CFU} / \mathrm{mL}$ ) after exposure to the antifungal irrigant

\begin{tabular}{lll}
\hline Test material (\%) & n & Mean colony count \pm SD \\
\hline A. vera 100 & 3 & $1374 \pm 571.982$ \\
A. vera 75 & 3 & $863 \pm 176.510$ \\
A. vera 50 & 3 & $1062 \pm 170.666$ \\
EDTA 17 & 3 & $160.67 \pm 8.963$ \\
C. albicans biofilm without treatment & 3 & $1852.67 \pm 90.163$ \\
\hline
\end{tabular}

${ }^{*} \mathrm{p}<0.05$, C. albicans: Candida albicans, A. vera: Aloe vera, CFU: Colony-forming unit

Table 2: Significance values of fungal colony quantities in C. albicans biofilm across groups

\begin{tabular}{llllll}
\hline Test material (\%) & C. albicans biofilm without treatment & A. vera 100\% & A. vera 75\% & A. vera 50\% & EDTA 17\% \\
\hline C. albicans biofilm without treatment & - & 0.638 & $0.015^{*}$ & 0.063 & 0.000 \\
A. vera 100 & 0.638 & - & 0.503 & 1.000 & $0.004^{*}$ \\
A. vera 75 & 0.015 & 0.503 & - & 1.000 & 0.121 \\
A. vera 50 & 0.063 & 1.000 & 1.000 & - & $0.028^{*}$ \\
EDTA 17 & 0.000 & $0.004^{*}$ & 0.121 & $0.028^{*}$ & - \\
\hline
\end{tabular}

* post hoc Tamhane $\mathrm{p}<0.05$, C. albicans: Candida albicans, A. vera: Aloe vera 


\section{CONFLICTS OF INTEREST}

There are no conflicts of interest to declare.

\section{REFERENCES}

1. Ghogre P. Endodontic mycology: A new perspective of root canal infection. Res Rev 2014;2014:1.

2. Torabinejade M, Walton RE. Endodontics Principles and Practice. $5^{\text {th }}$ ed. Missouri: Elsevier.

3. Waltimo TM, Sen BH, Meurman JH, Ørstavik D, Haapasalo MP. Yeast in apical periodontitis. Crit Rev Oral Biol Med 2003;14:128-37.

4. Sureshchandra B, Arun K. Antibacterial Efficacy of Aloe vera Extract on Resistantantimicrobial Strains in Endodontics. Mangalore: Department of Conservative Dentistry and Endodontics, A.J. Institute of Dental Sciences.

5. Waltimo TM, Haapasalo M, Zehnder M, Meyer J. Clinical aspect related to endodontic yeast infections. Endod Top 2004;9:66-78.

6. Sitara U, Hassan N, Naseem J. Anti-fungal activity of Aloe vera gel against plant pathogenic fungi. Pak J Bot 2011;43:2231-3.

7. Doddanna SJ, Patel S, Sundarrao MA, Veerabhadrappa RS. Antimicrobial activity of plant extracts on C. albicans: An in vitro study. Indian J Dent Res 2013;24:401-5.

8. Jose J, Krishnamma S, Peedikayil F, Aman S, Tomy N, Mariodan JP. Comparative evaluation of antimicrobial activity of qmix, $2.5 \%$ sodium hypochlorite, $2 \%$ chlorhexidine, guava leaf extract and aloevera extract against Enterococcus faecalis and C. albicans-An in-vitro study. J Clin
Diagn Res 2016;10:ZC20-3.

9. Hargreaves K, Berman L. Cohen's Pathways of the Pulp. $11^{\text {th }}$ ed. Missouri: Elsevier.

10. Ruddle CF. Endodontic Triad for Success: The Role of Minimally Invasive Technology; 2015. Available from: http://www.endoruddle. com/tc2pdfs/185/EndoTriad_May2015.pdf.

11. Sari FE. Minimum Inhibitory Concentration and Concentration Kill Minimal Aloe vera Leaf Extract Against C. albicans which is Isolated from the Oral Cavity Patient with HIV and C. albicans Strains ATCC 10231 [In Indonesia]. Jakarta: Fakultas Kedokteran Gigi Universitas Indonesia; 2009.

12. Stanley MC, Ifeanyi OE, Eziokwu OG. Antimicrobial effects of Aloe vera on some human pathogens. Int J Curr Microbiol Appl Sci 2014;3:1022-8.

13. Siqueira JR. Aetiology of root canal treatment failure: Why well-treated teeth can fail. Int Endod J 2001;34:1-10.

14. Sen BH, Piskin B, Demirici T. Observation of bacteria and fungi in infected root $\mathrm{c}$ canals and dentinal tubules by SEM. Endond Dent Traumatol 1995;11:6-9.

15. Sudarshan R, Annigeri RG, Vijayabala GS. Aloe vera in dentistry. Indian J Stomatol 2013;4:45-7.

16. Sujatha G, Kumar GS, Muruganandan J, Prasad TS. Aloe vera in dentistry. J Clin Diagn Res 2014;8:Z101-2.

17. Chhina S, Singh A, Menon I, Singh R, Sharma A, Aggarwal V. A randomized clinical study for comparative evaluationof Aloe vera and $0.2 \%$ chlorhexidine gluconatemouthwash efficacy on de-novo plaque formation. J Int Soc Preven Community Dent 2016;6:251-5. 